\title{
DESIGN OF DIFFERENT COMPENSATORS FOR DOUBLE INTEGRATOR PLANTS
}

\author{
Awad I. Saleh ; Mohamed M. M. Hasan ; Amer A. Ali \\ and Mostafa A. Ahmed \\ Department of Electrical Engneering, Faculty of Engneering, Assiut \\ University, Assiut, Egypt.
}

(Received April 6, 2006 Accepted April 18, 2006)

This paper describes the design and implementation of various type of controllers, used in controlling the double integrator system with input saturation none linearity. Two different types of controllers for the double integrator system will be discussed, conventional or classical controllers and intelligent controllers. The double integrator plant, which is one of the most fundamental systems in control applications, is considered here. Some of applications of the double integrator plant are, satellite control system [1],[2], single-degree-of-freedom translational [4], single-axis spacecraft rotation, alpha joint of Space station, inverted pendulum system with an on-off actuator, and, conventional hard disk drive with a single voice-coil-motor (VCM) actuator. First, the design of different conventional controllers for the double integrator plant with saturation nonlinearity will be presented. Then, the design and implementation of two types of Fuzzy Logic Controller (FLC) will be presented. Finally, PID controller for the Double Integrator system that is tuned using genetic algorithms will be presented. It was found that PID controller for the double integrator system that is tuned using genetic algorithms is better than the other controller.

\section{1- INTRODUCTION}

The input saturation problem is intrinsic to automatic control technology [7]. In fact no technological advance can circumvent rate and amplitude constraints on electromechanical actuators, furthermore, cost constraints often force control engineers to extract the best possible performance from components with limited capability, thus increasing the occurrence of saturation. The importance and pervasiveness of saturation is reflected by extensive research devoted to the problem.

The block diagram of the double Integrator plant under nominal conditions is shown in Fig. 1.

It is clear from Figure 1 that the equations of the double integrator are given by

$\dot{x}=A x+b \cdot \operatorname{sat}_{\varepsilon}(u), \quad y=c x$

Where $\quad x=\left[\begin{array}{l}x_{1} \\ x_{2}\end{array}\right], \quad A=\left[\begin{array}{ll}0 & 1 \\ 0 & 0\end{array}\right], \quad b=\left[\begin{array}{c}0 \\ 1 \\ m\end{array}\right], \quad c=\left[\begin{array}{ll}1 & 0 \\ 0 & 1\end{array}\right], \quad x_{1}$ and $x_{2}$ are the 


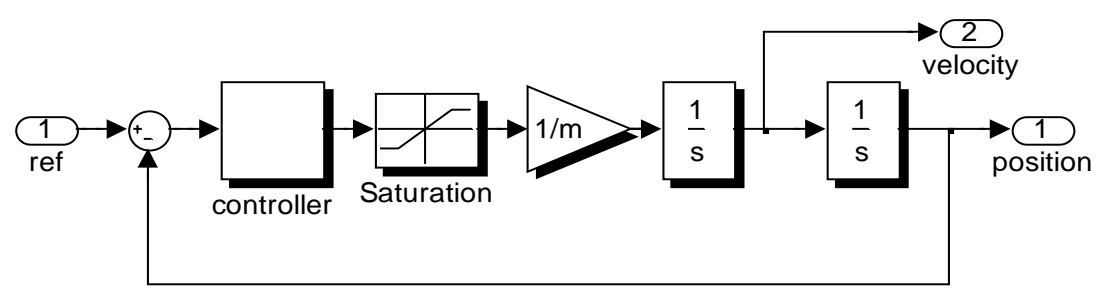

Fig. 1: The block diagram of the double Integrator plant under nominal conditions.

position and velocity, respectively, of a body having mass $\mathrm{m}$, and the saturation and sign functions are defined as

$$
\operatorname{sat}_{\varepsilon}(u)=\left\{\begin{array}{ll}
u & |u|<\varepsilon \\
\mathcal{E} \operatorname{sign}(u) & |u| \geq \varepsilon
\end{array} \text {, and } \operatorname{sign}(u)=\left\{\begin{array}{cc}
-1 & , u<0 \\
0 & , u=0 \\
1 & , u>0
\end{array}\right.\right.
$$

It is assumed that the control begins at time $\mathrm{t}=0$ with initial conditions $x_{1}(0)=x_{10}$ and $x_{2}(0)=x_{20}$. The saturation function, which enforces a unity constraint on the allowable input amplitude, provides a practically meaningful bound on control authority common to all controllers.

\section{2- CONVENTIONAL CONTROL OF DOUBLE INTEGRATOR SYSTEM}

In this section, the following controllers will be designed for the double integrator plant with saturation nonlinearity:

(1) the Proportional-Derivative (PD), Linear quadratic Gaussian (LQG), and trap door, as examples for Linear Controllers.

(2) Minimum time, minimum energy, discontinuous sliding mode, continuous sliding mode, saturation, homogeneous, and direct adaptive, as examples for Nonlinear Controllers.

\section{1-The Proportional-Derivative (PD) Controller [6]}

The Proportional-Derivative (PD) controller is given by

$$
u(t)=k_{1} x_{1}+k_{2} x_{2},
$$

Nominal tuning was performed by setting $k_{2}=-1$ and $k_{1}=-1.25$. It is clear from Eq. (3) that $u(t)$ is linear time-invariant control.

\section{2- Linear quadratic Gaussian (LQG) [2][5]}

The LQG regulator consists of an optimal state-feedback gain and a Kalman state estimator. To form the LQG regulator, simply connect the Kalman filter and LQoptimal gain LQG regulator has the following state space equations

$\dot{\hat{x}}=\left[A-K_{2} C-B K_{1}\right] \hat{x}+K_{2} \bar{y}$, and $\quad \hat{u}=-K_{1} \hat{x}$

It is clear from Eq. (4), that $\hat{u}(t)$ is linear time-invariant control.

\section{3- Trap Door Controller [9][10]}

The trap door controller state-space model:

$$
\dot{x}_{c}(t)=A_{c} x_{c}(t)+B_{c} y(t)
$$


$u(t)=C_{c}(t) x_{c}(t)+D_{c}(t) y(t)$

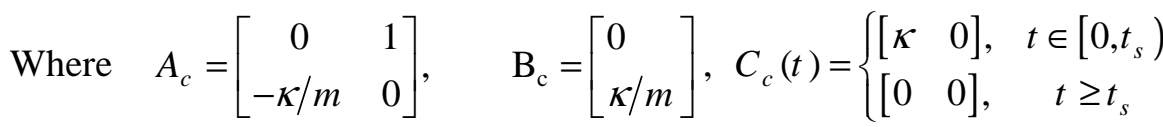

$D_{c}(t)=\left\{\begin{array}{cc}-K-\kappa & t \in\left[0, t_{s}\right) \\ 0, & t \geq t_{s} .\end{array} \quad\right.$, and $\quad x_{c}(t)=\left[\begin{array}{l}x_{c 1}(t) \\ x_{c 2}(t)\end{array}\right]$

It is clear from Eqs.(5), and (6), that, $u(t)$ the controller is linear time-varying controller.

\section{4- Minimum Time Controller [2]}

It is required to finding the optimal control signal defined by $|u(t)| \leq 1$ which transfers the double integrator system described by $\dot{x}_{1}(t)=x_{2}(t), \quad \dot{x}_{2}(t)=u(t)$ from any initial state $x_{0}$ to the origin in minimum time. let us define the switching function $s(x(t))$, as

$$
s(x(t)) \square x_{1}(t)+\frac{1}{2} x_{2}(t)\left|x_{2}(t)\right| .
$$

Thus, in terms of this switching function the optimal control law is

$$
u *(t)=\left\{\begin{array}{l}
-1, \text { for } x(t) \text { such that } s(x(t))>0 \\
+1, \text { for } x(t) \text { such that } s(x(t))<0 \\
-1, \text { for } x(t) \text { such that } s(x(t))=0 \text { and } x_{2}(t)>0 \\
0, \text { for } x(t)=0
\end{array}\right.
$$

It is clear from Eq. (7), that $u *(t)$ is nonlinear time-invariant control.

\section{5- Minimum Energy Controller [1]}

It is desired to find the optimal control $u *(t)$ which minimize the energy of control given by the performance index,

$J=\frac{1}{2} \int_{0}^{t_{f}} u^{2}(t) d t \quad$ It has been proven in .using the minimum principle that the optimal control $u *(t)$ which minimize $J$ is given by

$u *(t)= \begin{cases}\frac{-6}{\left(t_{f}-t\right)^{2}} x_{1}(t)-\frac{4}{\left(t_{f}-t\right)} x_{2}(t) & t \in\left[0, t_{f}\right] \\ 0 & t \geq t_{f}\end{cases}$

It is clear from Eq. (8), that $u *(t)$ is nonlinear time-varying control.

\section{6- Saturation Controller [6]}

For the double integrator system Saturation Controller given in [9] can be written as

$$
u(t)=-s a t_{u_{\max }}\left[b m x_{2}+s a t_{\varepsilon}\left(a m x_{1}+(a / b) m x_{2}\right]\right.
$$

Where $u_{\max }, \varepsilon$, a, and $b$ are constants. It is clear from Eq. (9), that $u(t)$ is nonlinear time-invariant control. Nominal tuning of the controller was performed by choosing 
$\varepsilon=0.49$. And $u_{\max }=1, a=b=1$, and the mass $\mathrm{m}$ was set to its nominal value of $m=1$.

\section{7- Discontinuous Sliding Mode Controller [3]}

The discontinuous Sliding mode controller For the double integrator system can be written as :

$$
u=-\lambda \dot{\tilde{x}}-k \operatorname{sgn}(\dot{\tilde{x}}+\lambda \tilde{x})=-\lambda \dot{x}-k \operatorname{sgn}(\dot{x}+\lambda x)
$$

Where $\tilde{x}(t)=x(t)-x_{d}=x(t)$, and $x_{d}=0$. It is clear from Eq. (10), that $u(t)$ is nonlinear time-invariant control.

\section{8- Homogeneous Controller [11]}

A smooth finite-time controller yielding homogeneous closed-loop dynamics for a chain of integrators was given in [15]. For the double integrator, this controller is given by

$$
\mathrm{u}=\phi\left(x_{1}, x_{2}\right)=-\operatorname{sign}\left(x_{2}\right)\left|x_{2}\right|^{\alpha}-\operatorname{sign}\left(x_{1}\right)\left|x_{1}\right|^{\frac{\alpha}{2-\alpha}}
$$

for $\alpha \in(0,1)$, the feedback law $\mathrm{u}$ renders the origin finite time stable for the double integrator. It is clear from Eq. (11), that $u(t)$ is nonlinear time-invariant control.

\section{9- Direct Adaptive Controller [12]}

A direct adaptive controller [12], for second-order systems in companion form with full state feedback is given by

$$
\begin{aligned}
& \dot{k_{1}}(t)=-(\operatorname{sign} b)\left[\lambda_{1} p x_{1}^{2}(t)+\left(\lambda_{1}+\lambda_{12} p\right) x_{1}(t) x_{2}(t)+\lambda_{12} x_{2}^{2}(t)\right], \\
& \dot{k_{2}}(t)=-(\operatorname{signb})\left[\lambda_{12} p x_{1}^{2}(t)+\left(\lambda_{12}+\lambda_{2} p\right) x_{1}(t) x_{2}(t)+\lambda_{2} x_{2}^{2}(t)\right], \\
& \dot{\phi}(t)=-(\operatorname{signb}) \lambda_{3}\left[p x_{1}(t)+x_{2}(t)\right],
\end{aligned}
$$

Where $\left[\begin{array}{ll}\lambda_{1} & \lambda_{12} \\ \lambda_{12} & \lambda_{2}\end{array}\right] \square(\Lambda / \Gamma)$ is positive definite and $\lambda_{3} \square \lambda>0$

And $u(t)=K(t) x(t)+\phi(t)$, Nominal tuning was performed empirically by setting $\lambda_{1}=0.25, \lambda_{2}=1, p=0.3$, and $\lambda_{12}=0$. It is clear that $u(t)$ is nonlinear timeinvariant control.

\subsection{0- Nominal Phase Portraits of The Controlled Double Integrator System}

The nominal value of the mass is $m=1$. For this nominal value, each controller is tuned to have good response with a unity saturation constraint enforced. Some of the controllers are "overturned" in the sense that the control signal u (prior to saturation) may have a magnitude greater than unity, in which case the saturation constraint is active.

The tuning is performed for a collection of 20 initial conditions equally spaced on a circle of radius 5 about the origin in the $\mathrm{x} 1$, $\mathrm{x} 2$ phase plane. The Achieved Settling Time (AST) is the maximum time for the trajectory to reach and remain within a circle of radius 0.01 , about the origin for the given collection of initial conditions. The 
nominal tuning objective is to minimize the Nominal Achieved Settling Time (NAST), which is the achieved settling time under nominal conditions. The block diagram of the double integrator system under nominal conditions is shown in figure 1. It is clear from Fig. 2, that, the double integrator system with these controllers is globally asymptotically stable, and the minimum time controller gives minimum NAST which equal to $13.02 \mathrm{sec}$.
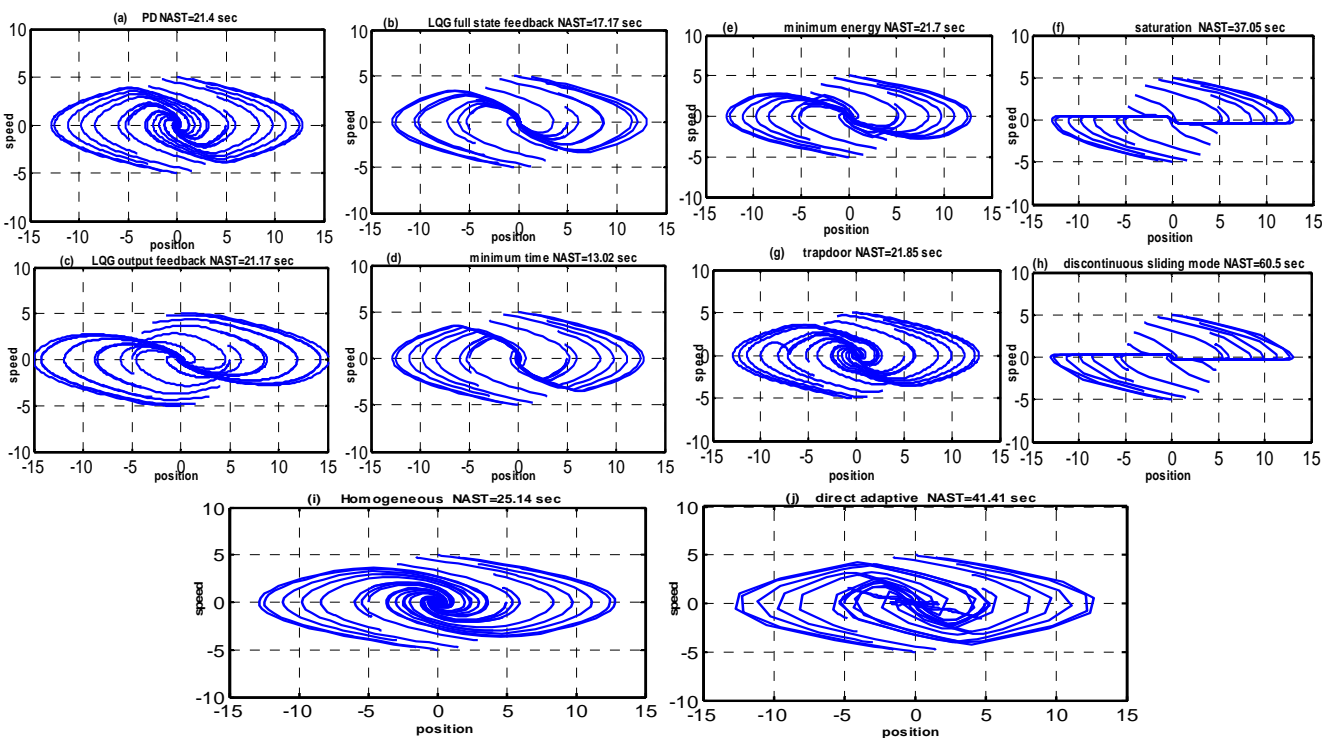

Fig. 2: Nominal phase portraits for the double integrator system with

(a) Proportional-Derivative (PD),

(b) Linear quadratic Gaussian (LQG) full state feed back,

(c) Linear quadratic Gaussian (LQG) output feed back, (d) Minimum time, (e) minimum energy,

(f) saturation, (g) trap door,

and (j) direct adaptive, controllers.

\subsection{1- Off-Nominal Stabilization for The Double Integrator System}

The block diagram of the double Integrator plant under off-nominal conditions is shown in Fig. 3. The off-nominal conditions for the Double Integrator plant, include inertia perturbation, real and imaginary pole perturbations, measurement delay, unmodeled dynamics, and input nonlinearities, the disturbance rejection and command-following abilities.

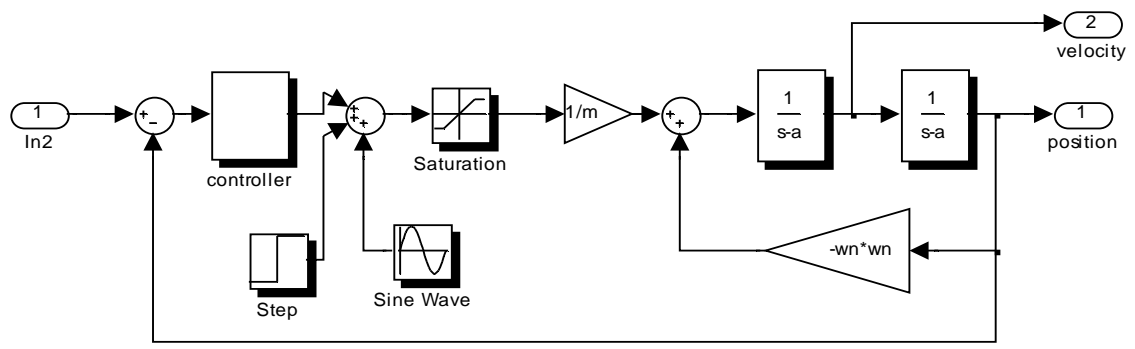

Fig. 3: The block diagram of the double Integrator plant under off-nominal conditions. 


\subsection{1- Robustness to Mass Variation}

The robustness due to mass variation of the double integrator system designed using different Controllers is measured by degradation of the Achieved Settling Time (AST) of the system due to variation in the mass, which has nominal value $m=1$. Tests were conducted for true mass values $m=\{0.1,0.25,0.5,1,1.5,2\}$, and the resulting degradation in the Achieved Settling Time (AST) for different controllers is dissipated in Fig. 4. It is clear from the figure that all controllers result in nearly the same AST. It is also clear from the Fig. 3, that PD, and LQG with full state feedback controllers result in least AST for values of $m>1$, and $m<1$, respectively.

The robustness due to pole location variation of the double integrator system designed using different controllers is measured by degradation of the Achieved Settling Time (AST) of the system due to variation in the Pole Location on the imaginary axis, and real axis, the plant transfer function are respectively given by:

$G_{p}(s)=\frac{1}{s^{2}+\omega_{n}^{2}}$, with $\omega_{n} \in[1,6], \quad$ and $G_{p}(s)=\frac{1}{(s+a)^{2}}$,

with $a \in[-0.2,0.2]$, the resulting degradation in the Achieved Settling Time (AST) are shown in Fig. 5a, and b. It is clear from Fig. 5a, that, the saturation and discontinuous sliding mode controllers fared better than the rest incase of variation in imaginary part of the poles location, and from Fig. 5b that, the saturation and minimum time controllers fared better than the rest incase of variation in real part of the poles location.

\subsection{2- Command Following}

The command following performance of the nominal double integrator system designed using different controllers is measured by applying a reference input signal see figure 1, and figure 2, namely steps, to the system and the output time response are computed and compared for different controllers used. The resulting output time responses are shown in Fig. 6. It is clear from the figure that all responses exhibit zero steady-state error for the nominal plant. It is also clear from the figure that the output response of the system designed with minimum time controller has the fastest response, nearly without overshoot, and with settling time equal $2 \mathrm{sec}$.
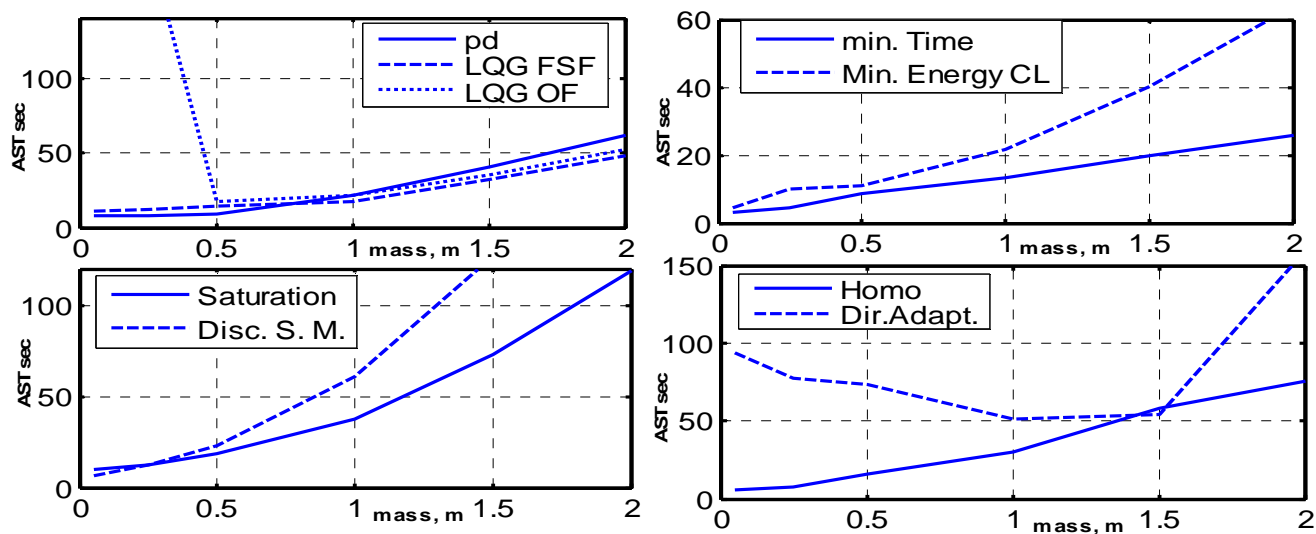

Fig. 4: Achieved Settling Time (AST) degradation due to mass variation Robustness to Pole Location Variation. 

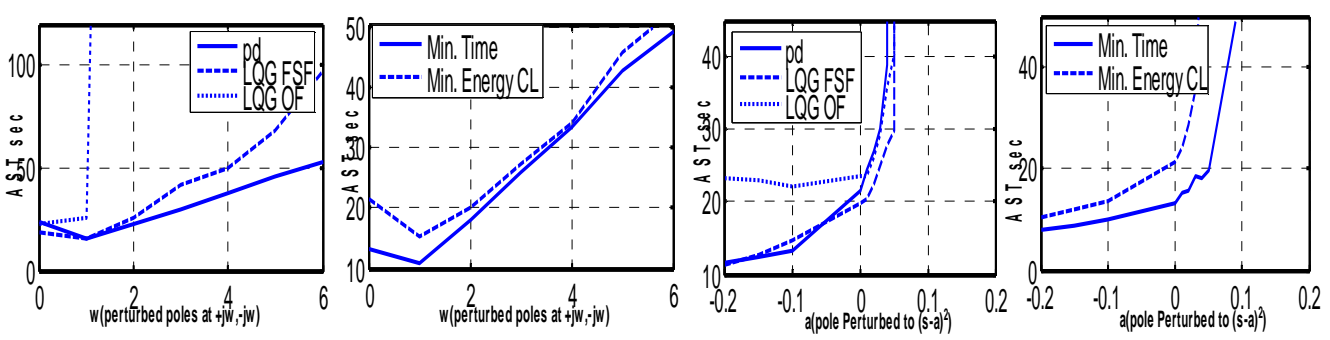

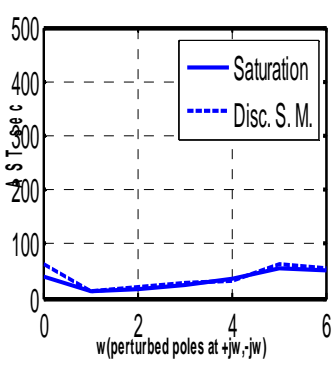

(a)

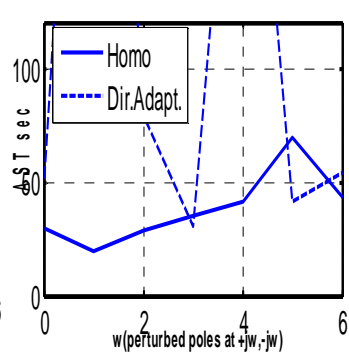

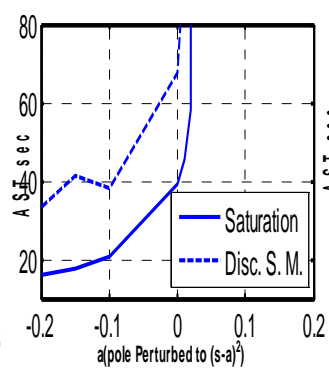

(b)

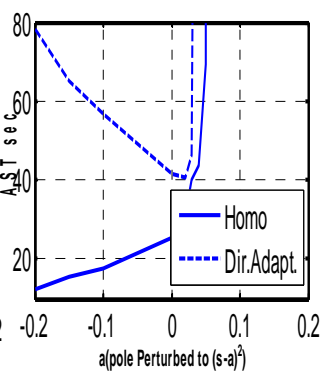

Fig. 5: Achieved Settling Time (AST) degradation due to (a) the imaginary part of, and (b) the real part of pole location.
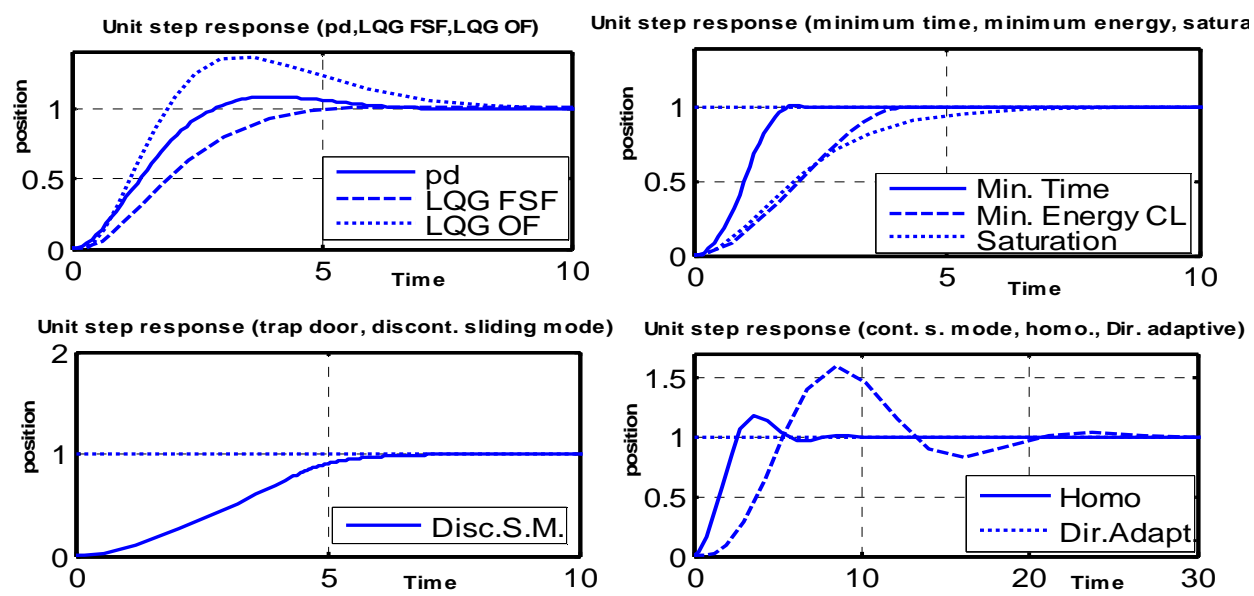

Fig. 6: The step response of the double integrator system with different controllers .

\subsection{3- Disturbance rejection}

The disturbance rejection performance of the double integrator system designed using different controllers, is measured by applying a disturbance signal see figure 6 , namely steps of magnitude 5 , and a sinusoid of magnitude 0.5 and frequency $0.1 \mathrm{~Hz}$, but an integrator loop is added to the system, and the output time response are computed and compared for controllers used. The resulting output time response is depicted in Fig. 7, and Fig. 8. it is clear from the figure that the system designed with minimum time controller fared best, canceling all of the disturbances completely. 

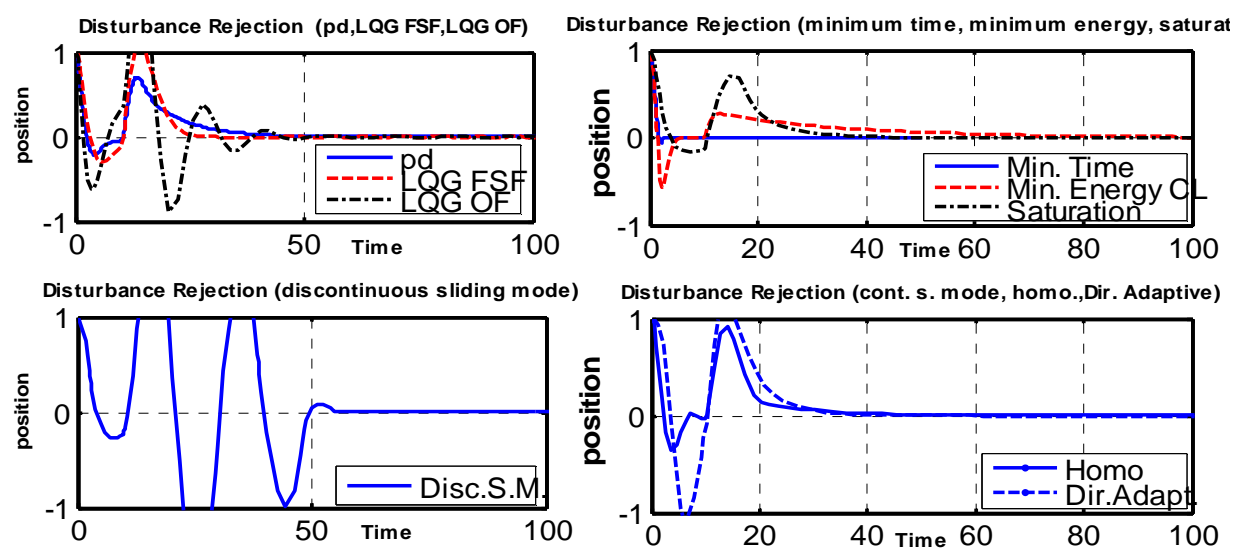

Fig. 7: disturbance rejection performance of the double integrator system designed using different controllers due to step disturbance of magnitude 5.
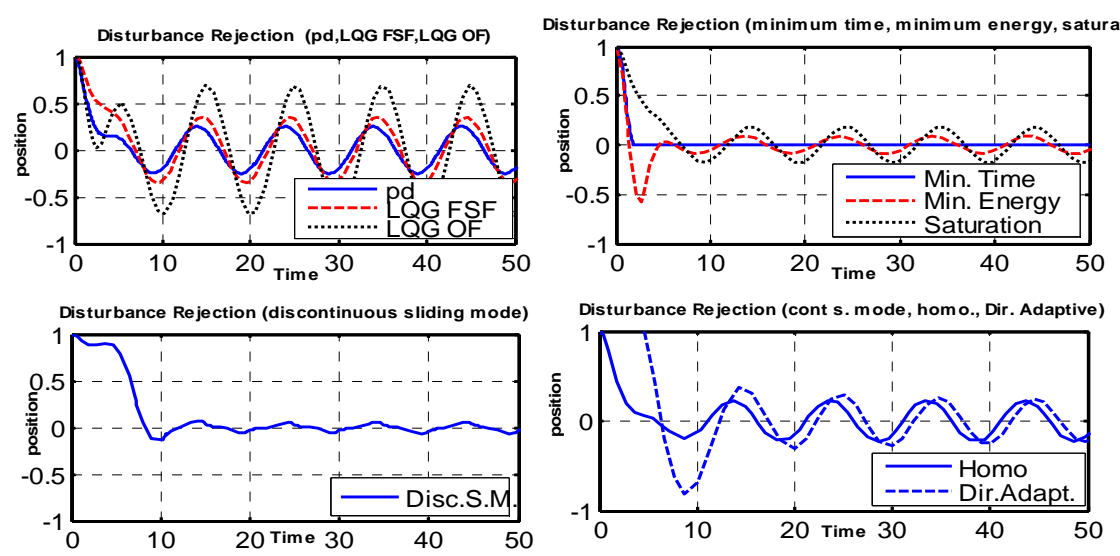

Fig. 8: Disturbance rejection performance of the double integrator system designed using different controllers due to sinusoid disturbance of magnitude 0.5 and frequency $0.1 \mathrm{~Hz}$.

\subsection{4- Unmodeled Dynamics}

The unmodeled dynamics are due to a flexible appendage [4]. Additional mass $m$ is appendage to the original mass through spring with stiffness values $k$. The transfer function of double integrator system with unmodeled dynamics is obtained from equation as

$$
\frac{Q_{1}(s)}{u(s)}=\left[\frac{s^{2} M+k}{s^{2} m\left(s^{2} M+k\right)+s^{2} M k}\right]
$$

The appendage mass values $M=0.2$, were considered, and stiffness values $k$ were considered in the range $k \in[0.4,1.4]$. It is clear from Fig. 9 that the LQG output feedback, and minimum energy closed-loop controllers performed poorly. Of the successful controllers, the PD and LQG full state feedback, and saturation controllers performed the best. 

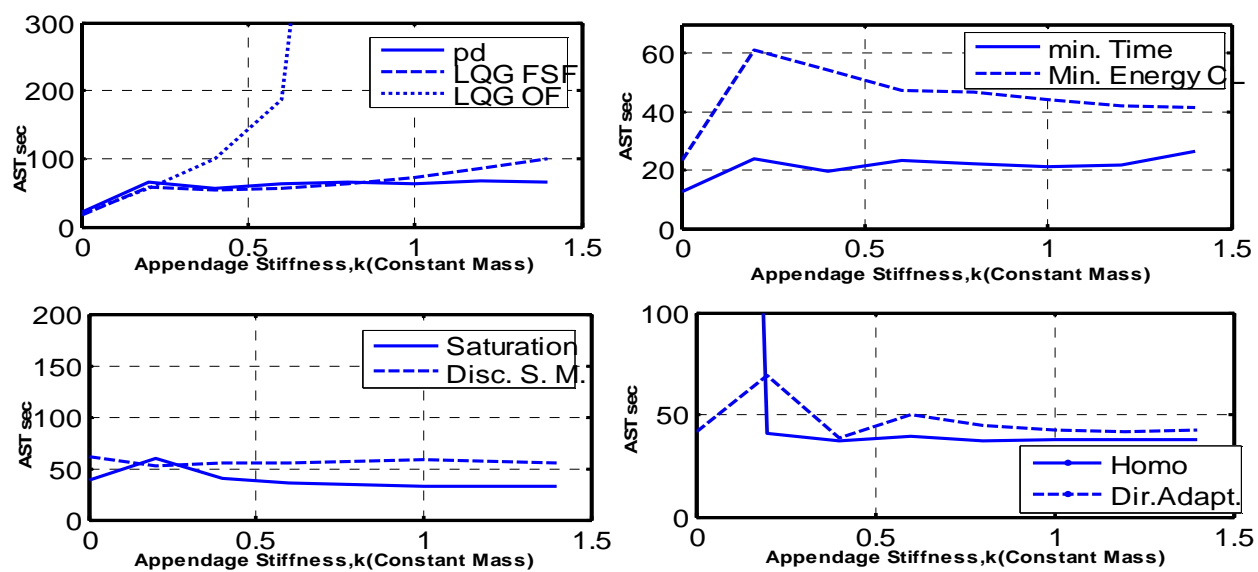

Fig. 9: Achieved Settling Time (AST) degradation due to flexible appendage.

\section{3- INTELLIGENT CONTROL OF DOUBLE INTEGRATOR SYSTEM}

In this section the following types of intelligent controllers will be designed for the double integrator system

(1) Adaptive Fuzzy Logic Control [13][14].

(2) PID Controller Tuning using Genetic Algorithms.

\section{1- Adaptive Fuzzy Logic Control (FLC) For The Double Integrator System [15][16][17]}

Adaptive control covers a set of techniques which provide a systematic approach for automatic adjustment of the controllers in real time, in order to achieve or to maintain a desired level of performance of the control system when the parameters of the process dynamic model are unknown and/or change in time, as shown in Fig. 10 adaptive control system is nonlinear since the parameters of the controller will depend upon measurements of system variables through the adaptation loop. In the case of PID controller the adaptation scheme will set the three gains of the controller. FLC contains a number of sets of parameters that can be altered to modify the controller performance. These are:

(1) The scaling factor for each variable.

(2) The fuzzy set representing the meaning of linguistic values.

(3) The If-THEN rules.

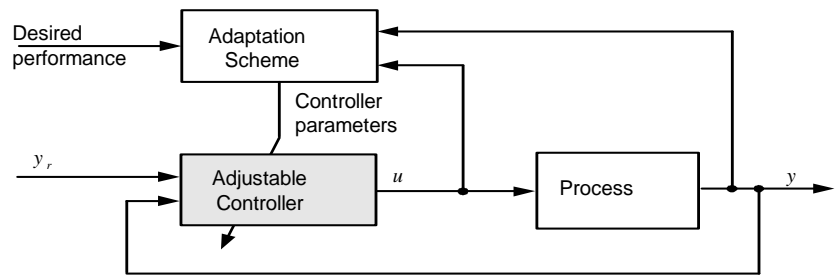

Fig. 10: An adaptive control system. 
The following types of Fuzzy Logic Controller (FLC) will be designed for the double integrator system:

(1) Proportional-Derivative-Self-Tuning Fuzzy Logic Controller (PDSTFLC) .

(2) Proportional-Derivative-Self-Tuning-Scaling Factors Fuzzy Logic Controller (PIDSTSFFLC).

\subsection{1- PD Self-Tuning Fuzzy Logic Controller (PDSTFLC) [16]}

The basic structure of the controller proposed here is identical to the conventional fuzzy PD controller except the self-tuning operation, which is shown in FigFig. 11, The proposed controller is tuned dynamically by adjusting its output scaling factor (SF) in each sampling instance by an updating factor $\alpha_{F}$. The value of $\alpha_{F} \square$ is determined by fuzzy rules defined on $e$ and $\Delta e$. The concentration is only on the tuning of output SF due to its strong influence on the performance and stability of the system. The output SF of the controller is modified by a self-tuning mechanism, which is shown by the dotted boundary in Fig. 11. The memberships (MF's) for the controller inputs, i.e. $e_{N}$ and $\Delta e_{N}$ and incremental change in controller output, i.e. $\Delta u_{N}$ are defined in the common normalized domain [-1,1], whereas the MF's for $\alpha_{F}$ defined in the normalized domain [0,1]. as shown in Fig. 12.

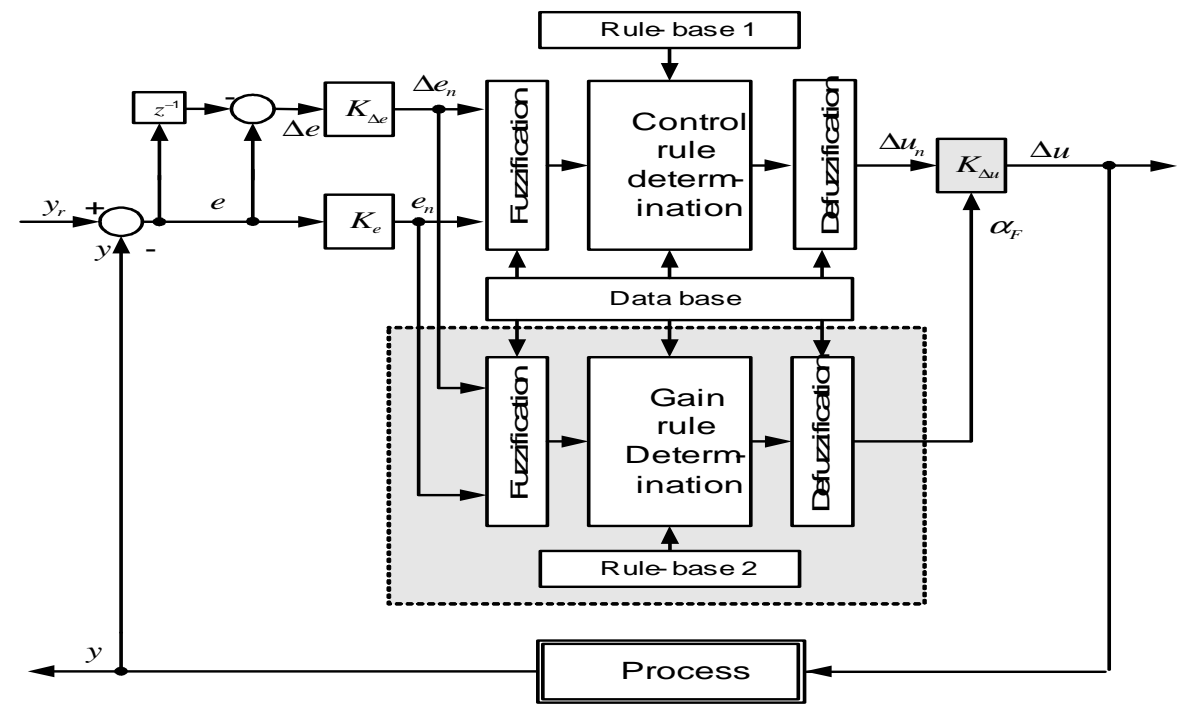

Fig. 11: The self-tuning PD Controller.
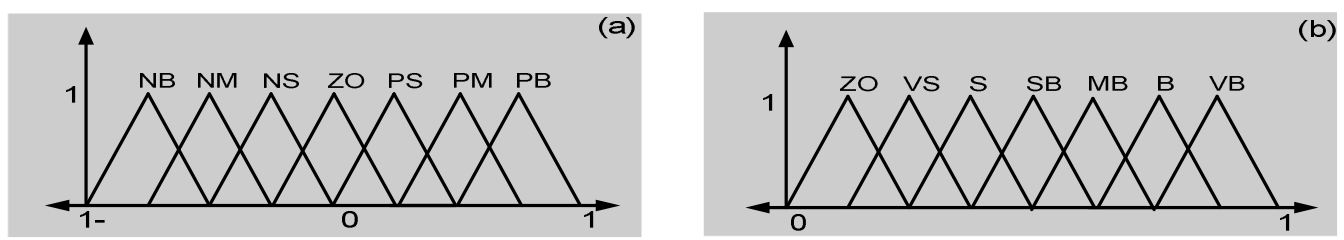

Fig. 12: Membership functions of

a) $e, \Delta e, \Delta u$ and b) gain updating factor $\alpha_{F}$. 
The relationships between the scaling factors $\left(K_{e}, K_{\Delta e}, K_{\Delta u}\right)$, and the input and output variables of the Self-Tuning Fuzzy PD-type Controller STFPDC are as follows:

$$
\begin{aligned}
e_{N} & =K_{e} \cdot e, \\
\Delta e_{N} & =K_{\Delta e} \cdot \Delta e, \\
\Delta u & =\left(\alpha_{F} \cdot K_{\Delta u}\right) \cdot \Delta u_{N}, \\
u(k) & =u(k-1)+\Delta u(k) .
\end{aligned}
$$

In this equation $k$ is a sampling instance and $\Delta u$ is an incremental change in the controller output, which is determined by the rules being of the form:

$R_{\Delta u}$ :IF $e$ is $L E$ and $\dot{e}$ is $L \Delta E$,THEN $\Delta u$ is $L U$.

The rule -base in is used for the computation of $\Delta u$. The gain-updating factor $\alpha_{F}$ is calculated by fuzzy rules, which are of the form:

$R_{\alpha_{F}}: I F e$ is LE and $\dot{e}$ is $L \Delta E, T H E N \alpha_{F}$ is $L \alpha_{F}$.

\subsection{2- PID Type Fuzzy Controller With Self-Tuning Scaling Factors (PIDSTSFFLC) [15],[17]}

The conventional fuzzy PID controller needs three inputs and the rule base has three dimensions, it is more difficult to design the rule-base. However, the fuzzy PID type controller has just two inputs and the rule-base is two dimensions. Its performance is also better than the fuzzy Pl and fuzzy PD controllers.

Fuzzy control design is composed of three important stages, namely,

(1) knowledge base design,

(2) Control tuning parameters, and

(3) Membership functions.

In order to make the fuzzy controller achieve the prospective target, we have to adjust these three stages of the fuzzy controller. But only the scaling factor adjustment can achieve the requisite of real time control. Therefore, if we want to apply the fuzzy control, the scaling factor of the fuzzy controller which can be adjusted is a necessary requirement because the changing of the membership functions is hard to improve the transient state. To design a PID fuzzy logic controller the PI fuzzy logic controller and the PD fuzzy logic controller must be connected in parallel, as shown in Fig.13.

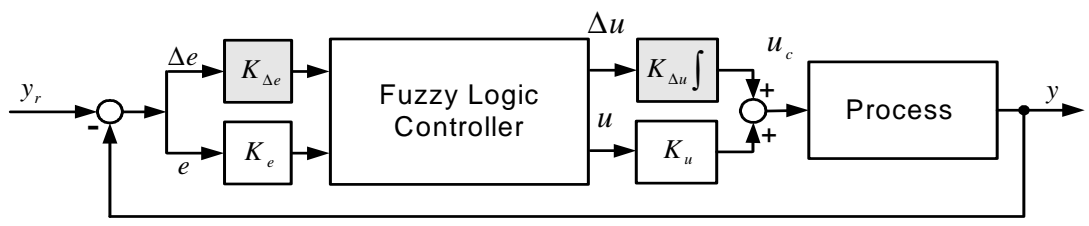

Fig. 13: PID fuzzy logic controller.

The output of the PID type fuzzy controller $u_{c}$ is calculated by

$R_{i}$ : IF $e$ is $L E_{i}$ and $\dot{e}$ is $L \Delta E_{i}, T H E N \Delta u$ is $C_{i}$.

$$
\alpha_{i}=\mu_{L E L i}(e) \wedge \mu_{L \Delta E}(\dot{e})
$$




$$
\begin{gathered}
\mu_{C_{i}^{\prime}}=\alpha_{i} \wedge \mu_{C_{i}} \\
\Delta u_{i}=\operatorname{COG}\left(C_{i}^{\prime}\right) \\
\Delta u=\frac{\sum_{i=1}^{N} \alpha_{i} \Delta u_{i}}{\sum_{i=1}^{N} \alpha_{i}}
\end{gathered}
$$

The $\operatorname{COG}\left(C_{i}^{\prime}\right)$ is the value obtained by defuzzifying $C_{i}^{\prime}$ with center-of-gravity method. The membership functions of the error, change rate of the error and the controller output are shown in Fig. 14, and the control rule is shown in Fig. 15.

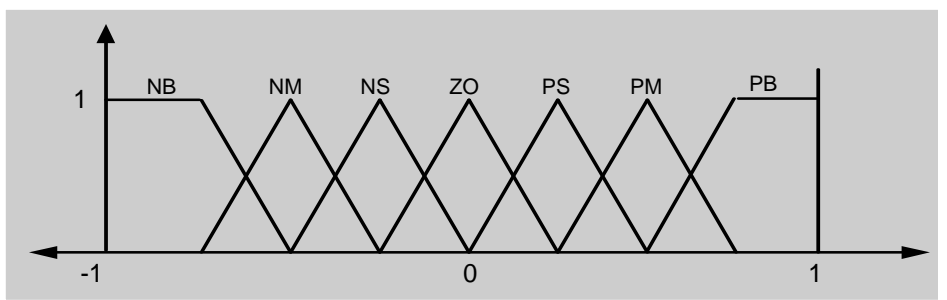

Fig. 14: The membership functions of $e, \Delta e$ and $u$.

There are on-line tuning methods of the fuzzy controller, but there are a few real-time scaling factor tuning methods. A self-tuning fuzzy controller is represented by the block diagram as shown in Fig. 15. There are several methods to tune the rules or control gains by complicated computing process but just changing the membership functions is hard to improve the transient state. Therefore, based on the same idea in the parameter adaptive method, define the functions $f_{\Delta e}(e(t))$ and $f_{\Delta u}(e(t))$ as given below.

$f_{\Delta u}(e(t))=a_{1}|e(t)|+a_{2}$,

$f_{\Delta e}(e(t))=b_{1}(1-|e(t)|)+b_{2}$

where $a_{1}, a_{2}, b_{1}$ and $b_{2}$ are all positive constants.

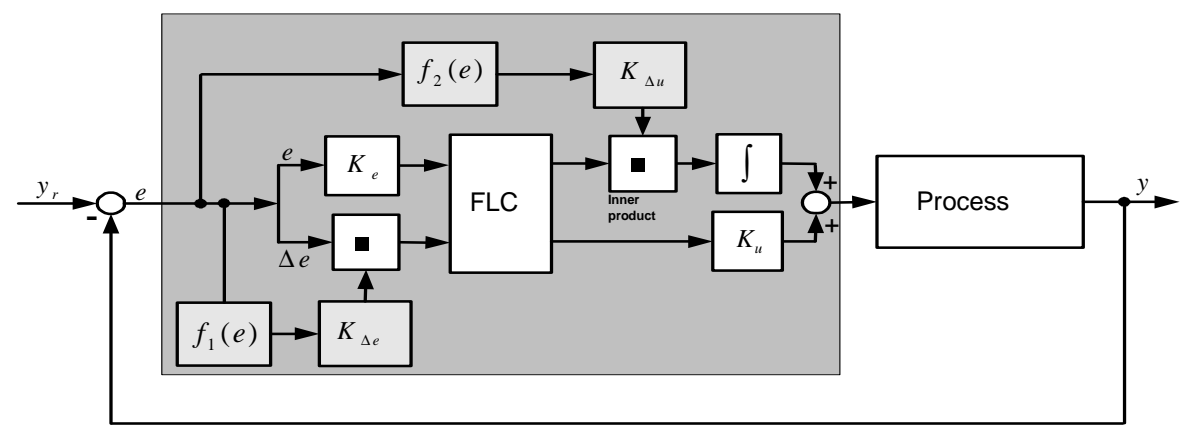

Fig. 15: The PID type fuzzy control system with function tuner. 
The self-tuning scaling factors changing with time are described as follows:

$$
\begin{aligned}
& K_{\Delta e}(t)=f_{\Delta e}(e(t)) K_{\Delta e o} \\
& K_{\Delta u}(t)=f_{\Delta u}(e(t)) K_{\Delta u o}
\end{aligned}
$$

where $K_{\Delta e o}$ and $K_{\Delta u o}$ are the initial values of the scaling factors $K_{\Delta e}$ and $K_{\Delta u}$ respectively. The objective of the function $f_{\Delta u}(e(t))$ is to decrease the $K_{\Delta u}$ with the change of error. In the other words, the error will be zero and $f_{\Delta u}(e(t))$ will eventually be equal to $a_{2}$. However, the function $f_{\Delta e}(e(t))$ is the inverse objective, in the steady state, the $f_{\Delta e}(e(t))$ will be equal to $\left(b_{1}+b_{2}\right)$. In the beginning $e=1$, and in the steady state $e=0$. From these conditions the parameters $a_{1}, a_{2}, b_{1}$ and $b_{2}$ are determined as follows:

$$
\begin{aligned}
& K_{\Delta u}^{\max }=\left(b_{1}+b_{2}\right) K_{\Delta u o}, K_{\Delta u}^{\min }=b_{2} K_{\Delta u o} \Rightarrow b_{1}=\frac{K_{\Delta u}^{\max }-K_{\Delta u}^{\min }}{K_{\Delta u o}} \\
& K_{\Delta e}^{\max }=\left(a_{1}+a_{2}\right) K_{\Delta e o}, K_{\Delta e}^{\min }=a_{2} K_{\Delta e o} \Rightarrow a_{1}=\frac{K_{\Delta e}^{\max }-K_{\Delta e}^{\min }}{K_{\Delta e o}}
\end{aligned}
$$

Determination of the initial values of the stated above controller parameters will be discussed by application to the double integrator system in the next sections

\subsection{3- Nominal Stabilization for the Double Integrator System with FLC}

The resulting Nominal Phase Portraits for the double integrator system with Fuzzy Logic Controllers (FLC) is shown in Fig. 16. It is clear from the figure that, the double integrator system with these controllers is globally asymptotically stable, and the PDSTFLC will give minimum NAST which equal to $25.4 \mathrm{sec}$.

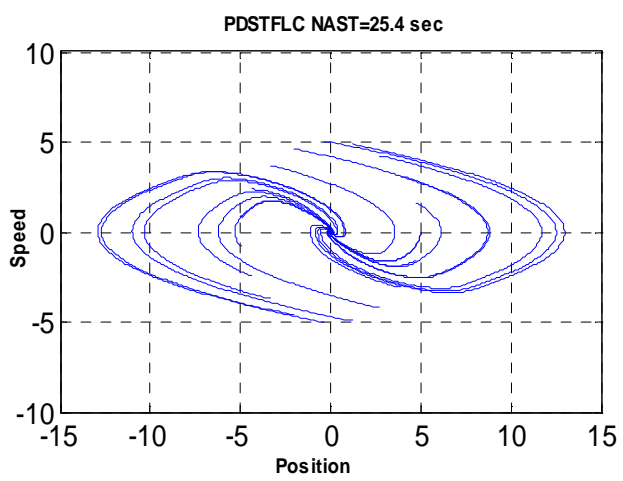

(a)

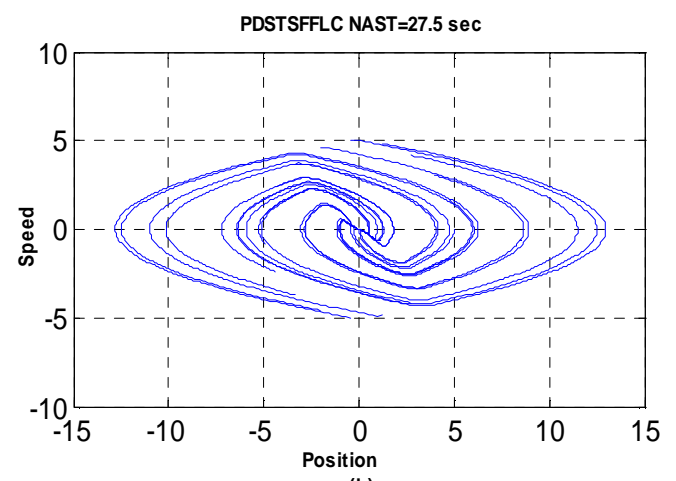

(b)

Fig. 16: Nominal phase portraits for the double integrator system with (a) PDSTFLC, (b) PDSTSFFLC. 


\subsection{4- Off-Nominal Stabilization for the Double Integrator System with FLC}

\section{Robustness to Mass Variation}

It is clear from Fig. 17 that all controllers result in nearly the same AST. It is also clear from the figure that PDSTFLC, and PDSTSFFLC result in nearly the same AST for values of $m>1$, and $m<1$, respectively.

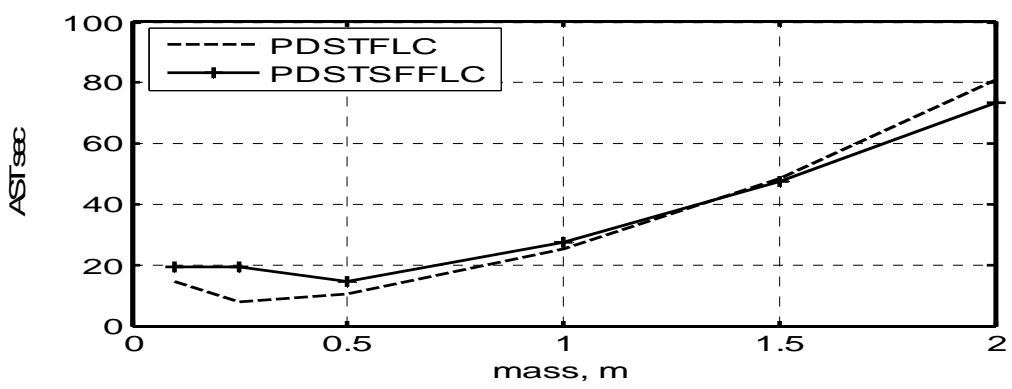

Fig. 17: Achieved Settling Time (AST) degradation due to mass variation.

\section{Robustness to Pole Location Variation}

The resulting degradation in the Achieved Settling Time (AST) for different controllers in the two cases (imaginary part, and real part variation) are shown in Fig. 18a, and b. It is clear from the figure that the PDSTFLC, and PDSTSFFLC fared better.
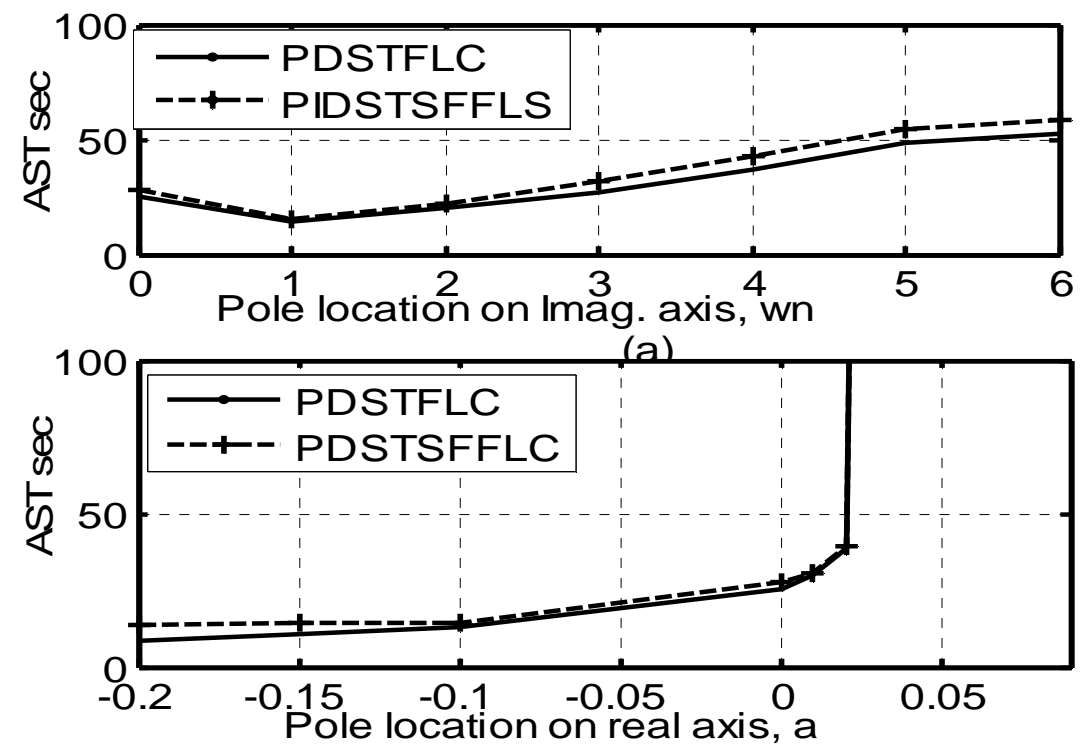

Fig.18: Achieved Settling Time (AST) degradation due to (a) the imagenary part of, and (b) the real part of pole location. 


\section{Command Following}

The resulting output time response are shown in Fig. 19 it is clear from the figure that all responses exhibit zero steady-state error for the nominal plant. It is also clear from the figure that the output response of the system designed with PIDSTSFFLC has the fastest response without overshoot.

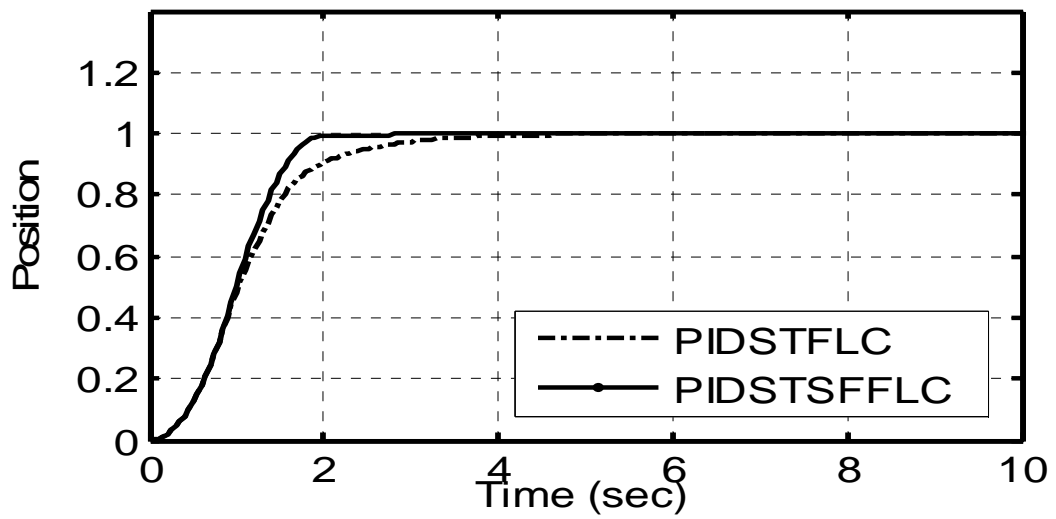

Fig. 19: The step response of the double integrator system with two (FLC).

\section{Disturbance rejection}

The resulting output time responses are depicted in Fig. 20, and Fig. 21 it is clear from the figures that the system designed with PIDSTSFFLC fared best, canceling all of the disturbances completely.
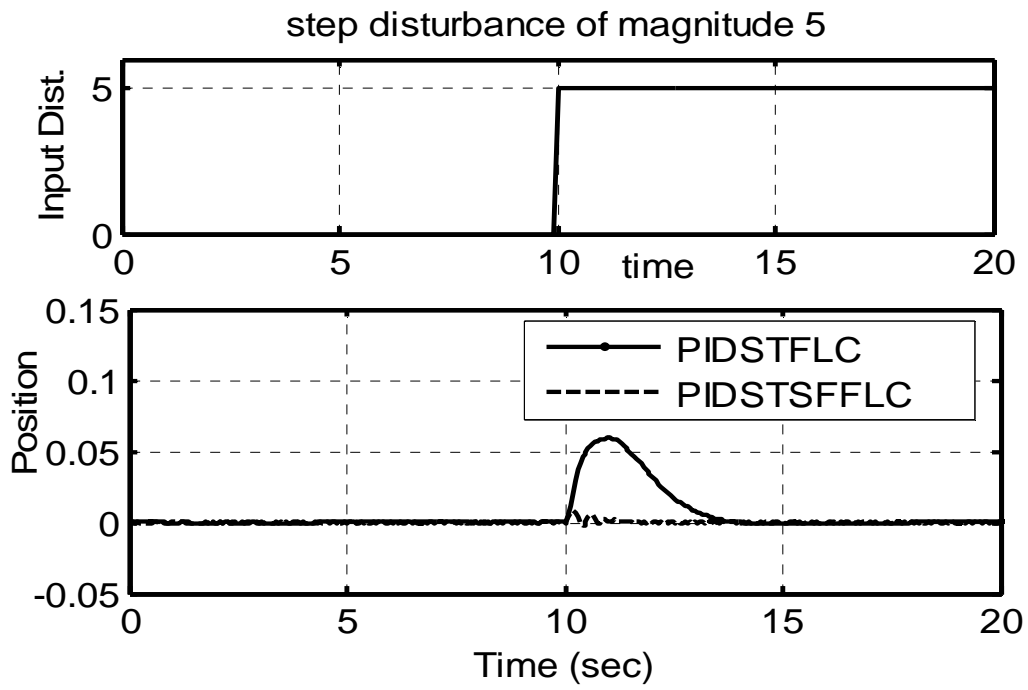

Fig. 20: Disturbance rejection performance of the double integrator system designed using two Fuzzy Logic Controllers (FLC) due to step disturbance of magnitude 5. 


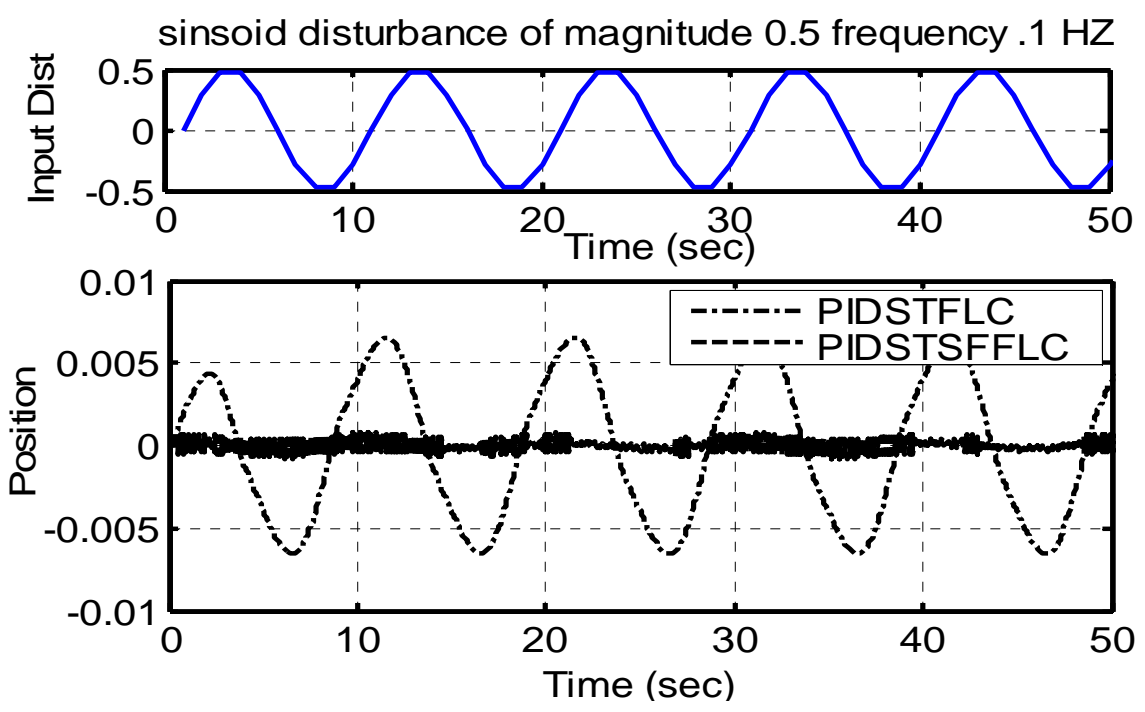

Fig. 21: Disturbance rejection performance of the double integrator system designed using two Fuzzy Logic Controllers (FLC) due to sinusoid disturbance of magnitude 0.5 and frequency $0.1 \mathrm{~Hz}$.

\section{2- Development of Genetic Algorithm for PID Tuning [18],[19][20]}

To aid with the development of this thesis, a system was chosen at random and a PID controller was designed for it using conventional methods. A genetic algorithm was then created to evaluate the PID coefficients of the same system. In the following sub sections the design of PID controller using two different techniques will be compared.

\subsection{1- design of PID controller using Ziegler-Nichols method}

The Ziegler-Nichols tuning method was the 'conventional' method used to evaluate the PID gains for the system [22]. If we discard the saturation nonlinearity at input of the system then Using the 'rlocfind' command in Matlab, the crossover point $j \omega_{c r}$ of the system were is arbitrarily chosen to adjust the gain at $K_{c r}=1$ and found to be $j 1.05$. With a frequency $\left(\omega_{c}\right)$ of $1.05 \mathrm{rad} / \mathrm{s}$, the period $P_{c r}$ is calculated as:

$$
P_{c r}=\frac{2 \pi}{\omega_{c}}=6 \mathrm{sec}
$$

The Ziegler-Nichols PID tuning parameters:

$$
K_{P}=0.6 K_{c r}, \quad T_{I}=P_{c r} / 2, \quad T_{D}=P_{c r} / 8
$$

Using the relationship $K_{I}=K_{P} / T_{I}$ and $K_{D}=K_{P} T_{D}$ the PID gains can be evaluated. Table1 shows the PID gain values for the system G(s). A number of objective functions were created in order to evaluate the PID values chosen by the Genetic Algorithm. 
Table1: Ziegler-Nichols PID Gain values

\begin{tabular}{|l|l|l|l|}
\hline controller & $K_{P}$ & $K_{I}$ & $K_{D}$ \\
\hline PID & 0.6 & 0.18 & 0.45 \\
\hline
\end{tabular}

\section{Performance Indices}

To optimize the performance of a PID controlled system, the PID gains of the system are adjusted to minimize a certain performance index. The performance index is calculated over a time interval; $T$, normally in the region of $0 \leq T \leq t_{s}$ where $t_{S}$ is the settling time of the system. The performance indices used were:

\section{Integral of Time by Absolute Error (ITAE)}

$$
I_{\text {ITAE }}=\int_{0}^{T} t|e(t)| d t
$$

The ITAE weights the error with time and hence emphasizes the error values later on in the response rather than the initial large errors.

\section{Integral of Absolute Error (IAE)}

$$
I_{\text {IAE }}=\int_{0}^{T}|e(t)| d t
$$

IAE gets the absolute value of the error to remove negative error components. IAE is a good criterion for simulation studies.

\section{Integral of Square Error (ISE)}

$$
I_{\text {ISE }}=\int_{0}^{T} e^{2}(t) d t
$$

The ISE squares the error to remove negative error components. ISE discriminates between over-damped and under damped systems.

\section{Mean of the Square of the Error (MSE)}

$$
I_{M S E}=\frac{1}{n} \sum_{j=1}^{n}\left(e\left(t_{j}\right)\right)^{2}
$$

MSE reflects all variation and deviation from the target value.

\section{Evaluation of Performance Criterion on Double Integrator System}

An experiment was undertaken to evaluate which of the four performance criterion produce the best results when used in conjunction with a Genetic Algorithm. An objective function was created for each individual performance criterion as depicted in: PID_objfun_ITAE.m, PID_objfun_IAE.m, PID_objfun_ISE.m and PID_objfun_MSE.m 


\section{Step Response}

The same Genetic Algorithm, Initial_PID_GA.m, [21] was used for each objective function. Fig. 22 shows an example of the converging through generations when the MSE objective function is used. Also Fig. 23 distinguishes the step responses of the double integrator plant with the Ziegler-Nichols and Genetic Algorithm tuned PID-controllers. Table 2 shows final value of gains of the Ziegler-Nichols and Genetic Algorithm tuned PID-controllers. The step response characteristics of the double integrator plant designed using Ziegler-Nichols [22] and Genetic Algorithm tuned PIDcontrollers are given in Table 3.
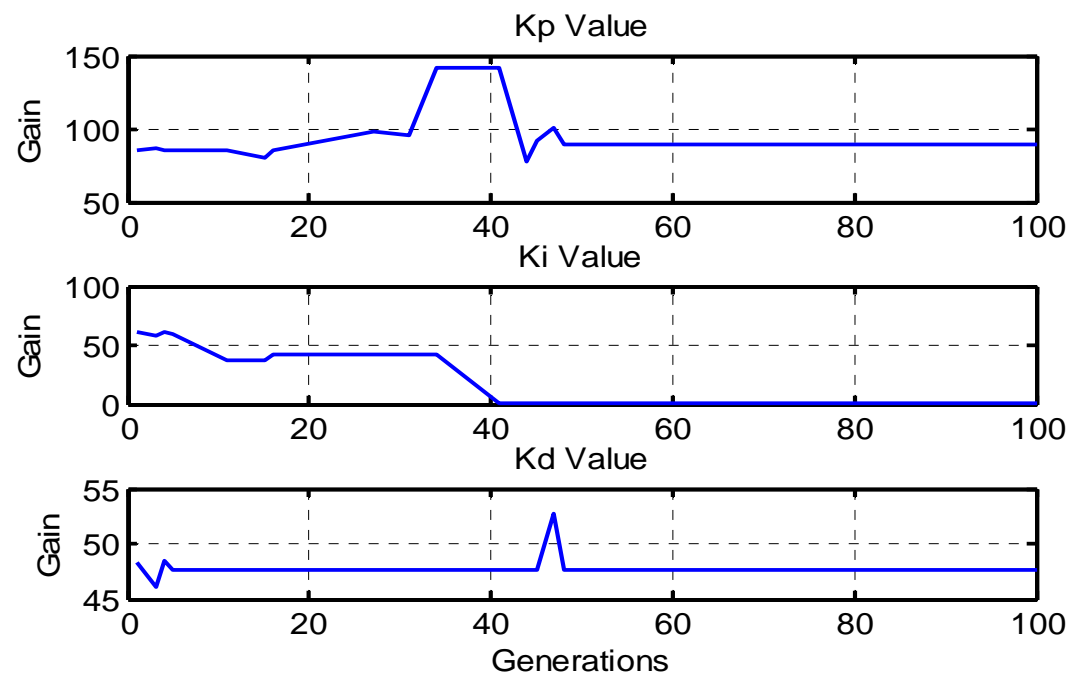

Fig. 22: Illustration of the Genetic Algorithm converging through generations when the MSE objective function is used.

(a) Step response ITAE objective function

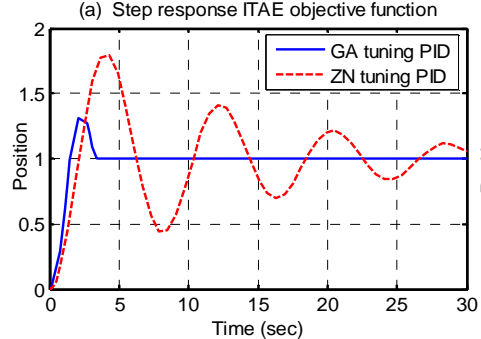

(c) Step response ISE objective function

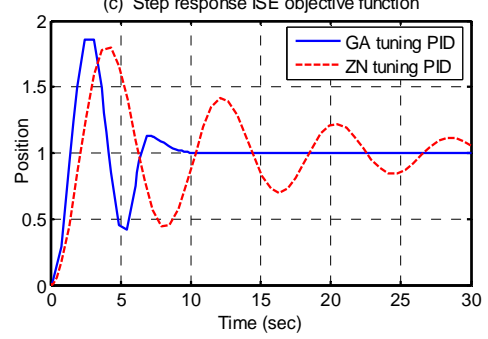

(b) Step response IAE objective function

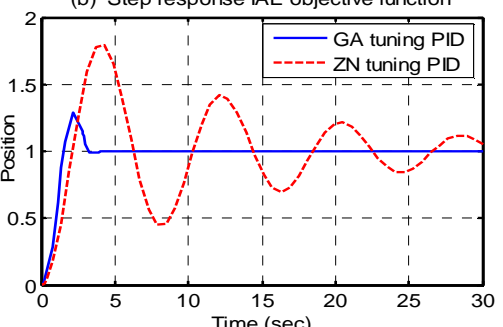

(d) Step response MSE objective function

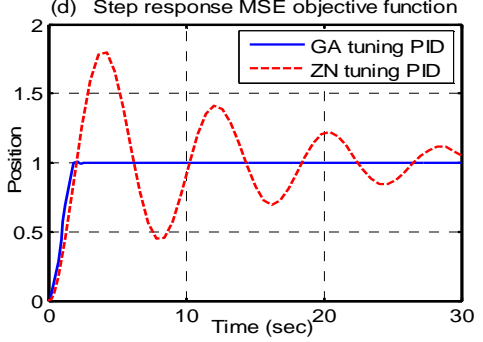

Fig. 23: Graph of Ziegler-Nichols designed PID controller Vs GA tuned PID Controller using (a) ITAE, (b) IAE, (c) ISE and (d) MSE as performance criterion. 
Table 2: final value of gains of the Ziegler-Nichols and Genetic Algorithm tuned PID-controllers.

\begin{tabular}{|c|c|c|c|c|c|}
\hline Method & $\begin{array}{c}\text { Ziegler-Nichols } \\
\text { tuned } \\
\text { PID-controller }\end{array}$ & $\begin{array}{c}\text { GA-tuned } \\
\text { PID-controller } \\
\text { based on } \\
\text { ITAE-obj. fun. }\end{array}$ & $\begin{array}{c}\text { GA-tuned } \\
\text { PID-controller } \\
\text { based on } \\
\text { IAE-obj. fun }\end{array}$ & $\begin{array}{c}\text { GA-tuned } \\
\text { PID-controller } \\
\text { based on } \\
\text { ISE-obj. fun }\end{array}$ & $\begin{array}{c}\text { GA-tuned } \\
\text { PID-controller } \\
\text { based on } \\
\text { MSE-obj. fun }\end{array}$ \\
\hline$K_{P}$ & 0.6000 & 134.6921 & 114.8462 & 31.2593 & 148.4049 \\
\hline$K_{I}$ & 0.1800 & 49.6244 & 0.5796 & 24.0266 & 2.3316 \\
\hline$K_{D}$ & 0.4500 & 51.6439 & 30.0567 & 16.8502 & 77.2611 \\
\hline
\end{tabular}

Table 3: The step response characteristics of the double integrator plant designed using Ziegler-Nichols and Genetic Algorithm tuned PID-controllers.

\begin{tabular}{|l|c|c|c|c|c|}
\hline $\begin{array}{l}\text { Step } \\
\text { Response } \\
\text { Characteristic }\end{array}$ & $\begin{array}{c}\text { Ziegler-Nichols } \\
\text { tuned } \\
\text { PID-controller }\end{array}$ & $\begin{array}{c}\text { GA-tuned } \\
\text { PID-controller } \\
\text { based on } \\
\text { ITAE-obj. fun. }\end{array}$ & $\begin{array}{c}\text { GA-tuned } \\
\text { PID-controller } \\
\text { based on } \\
\text { IAE-obj. fun }\end{array}$ & $\begin{array}{c}\text { GA-tuned } \\
\text { PID-controller } \\
\text { based on } \\
\text { ISE-obj. fun }\end{array}$ & $\begin{array}{c}\text { GA-tuned } \\
\text { PID-controller } \\
\text { based on } \\
\text { MSE-obj. fun }\end{array}$ \\
\hline Rise Time sec & 1.4000 & 0.6934 & 0.8493 & 0.6000 & 1.3000 \\
\hline$\%$ Overshoot & 70.8532 & 57.6609 & 29.1093 & 86.0494 & 0.0000 \\
\hline Settling Time sec & 45.000 & 3.5284 & 3.0169 & 9.3344 & 1.8119 \\
\hline Peak Time sec & 4.2965 & 2.8380 & 2.2063 & 2.4622 & ------ \\
\hline
\end{tabular}

Under the conditions of this study, the double integrator system designed using Genetic Algorithm tuned PID-controllers result in better performance than the system designed using Ziegler-Nichols tuned PID-controller. It can be seen from Fig. 23 that the IAE and MSE objective functions perform nearly the same, having a smaller rise time, smaller overshoot and smaller settling time than the other controllers. Each of the Genetic Algorithm tuned PID-controllers outperforms the Ziegler-Nichols tuned controller. The MSE objective function was chosen as the primary performance criterion for the remainder of this paper due to its smaller rise time and smaller overshoot than any other method in conjunction with a slightly faster compile time due to there being just one multiplication to be carried after the error has been calculated.

\section{Disturbance Rejection}

Two types of disturbances were applied to the double integrator plant, specifically, steps of magnitude 5, and a sinusoid of magnitude 0.5 and frequency 0.1 Hz. It is clear from the Fig. 24 that GA tuned PID controller based on the MSE objective function fared the best, canceling nearly all of the disturbances.

\section{Nominal Phase Portrait}

The nominal tuning objective is to minimize the nominal achieved settling time (NAST), which is the achieved settling time under nominal conditions, as shown in Fig. 25.

It was determined that the Mean Square Error (MSE) performance criterion based objective function produced the most effective PID controllers when compared with other performance criterion i.e. IAE, ITAE and ISE. 


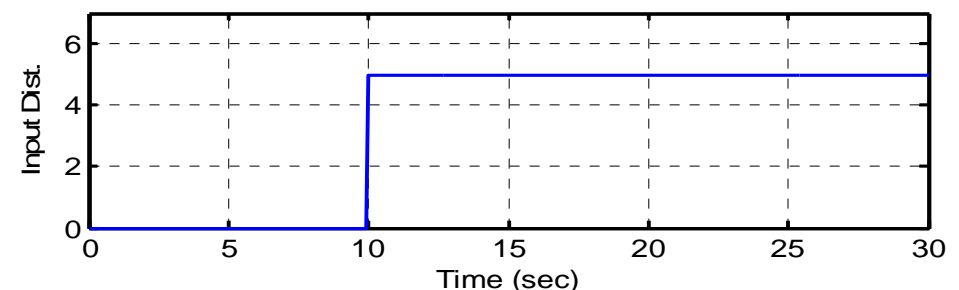

(a) Disturbance Rejection (step $=5$ )
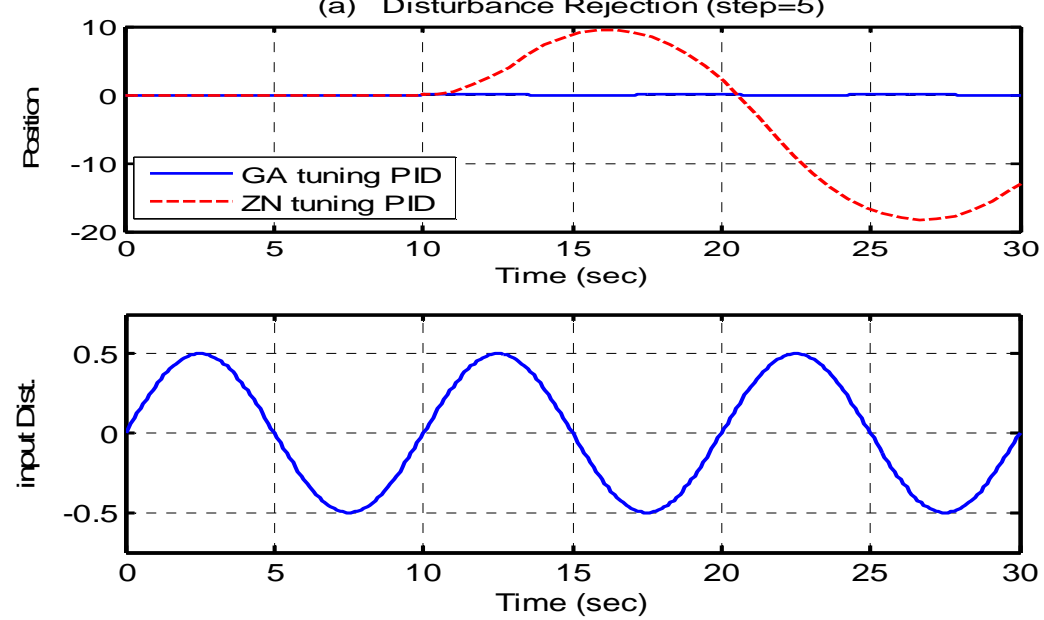

(b) Disturbance rejection (sine with magnitude $=0.5$ )

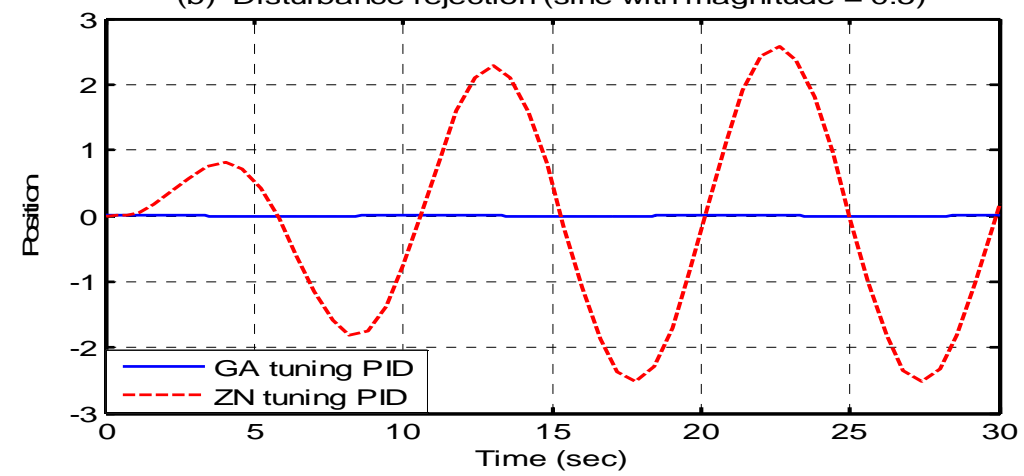

Fig. 24: Disturbance rejection the double integrator system designed using GA and Ziegler-Nichols tuned PID-controllers magnitude 0.5 and frequency $0.1 \mathrm{~Hz}$.

(a) step of magnitude 5

b) sinusoid of

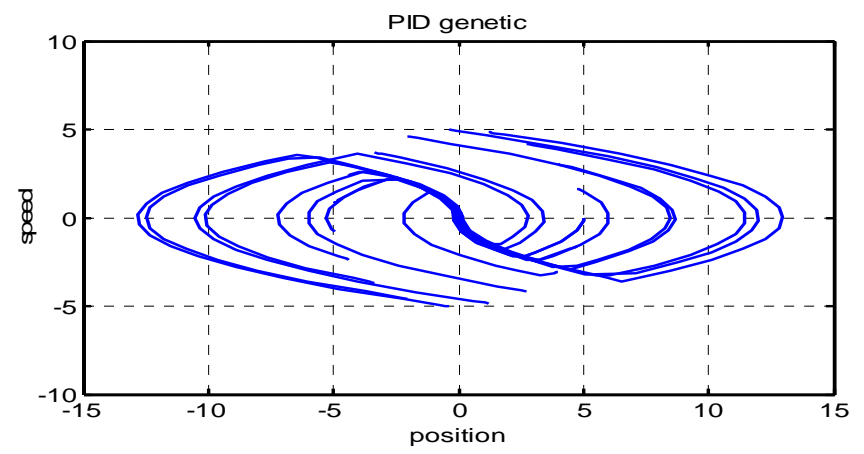

Fig. 25: Nominal Phase Portrait NAST=17 sec. 


\section{4- CONCLUSION}

The performance of the double integrator system designed with each of the above Controllers compared at nominal stabilization and off-nominal stabilization conditions. Also the performance of the designed system with different controllers, regarding disturbance rejection compared when the integral action is present in the controller. First, the nominal conditions are specified, and each controller is tuned to minimize the worst-case time to reach the origin from a set of initial conditions located on a circle of specified radius in the position/velocity phase plane with a constraint on input amplitude, it is clear that, the double integrator system designed with each of the above Controllers is globally asymptotically stable. And the double integrator system designed using Genetic Algorithm tuned PID-controllers result in better performance than the other controllers.

Next, each nominally tuned controller is tested for stabilization under a set of off-nominal conditions. These conditions include inertia perturbation, real and imaginary pole perturbations, measurement delay, unmodeled dynamics, and input nonlinearities. For these off-nominal conditions, the command-following with step input and disturbance rejection abilities of each controller with steps and sinusoids will be presented And the double integrator system designed using Genetic Algorithm tuned PID-controllers fair the best than the other controllers .

\section{5- REFERENCES}

[1] M. Athans and P.L. Falb, Optimal Control: An Introduction to the Theory and Applications. New York: McGraw Hill, 1966.

[2] D.E. Kirk, Optimal Control Theory: An Introduction. Englewood Cliffs, NJ: Prentice-Hall, Inc 1970.

[3] J.-J.E. Slotine and W. Li, Applied Nonlinear Control. Menlo Park, CA: Prentice Hall, Inc 1991.

[4] W.T. Thomson, Mechanical Vibrations. Englewood Cliffs, NJ: Prentice-Hall, 1953.

[5] Andrew P. Sage, Chelsea C. White, Optimum system Control. Englewood Cliffs, NJ: Prentice-Hall, Inc. 1977.

[6] A.R. Teel, Global stabilization and restricted tracking for multiple integrators with bounded controls, Syst. Contr. Lett., vol. 18, pp. 165-171, 1992.

[7] F. Tyan and D.S. Bernstein, "Global stabilization of systems containing a double integrator using a saturated linear controller," Int. J. Robust Nonlinear Contr., vol. 9, pp. 1143-1156, 1991.

[8] B. Aguirre, J. Alvarez-Ramirez, G. Fernandez, and R. Suarez, "First harmonic analysis of linear control systems with high-gain saturating feedback," Int. J. Bifurcation Chaos, vol. 7, pp. 2501-2510, 1996.

[9] R.T. Bupp, D.S. Bernstein, V.-S. Chellaboina, andW.M. Haddad, "Finite settling time control of the double integrator using a virtual trap door absorber," IEEE Trans. Automat. Contr., vol. 45, pp. 776-780, Apr. 2000.

[10] R. T. Bupp, D. S. Bernstein, W. M. Haddad, and V. Chellaboina, "Resetting virtual absorbers for control," in Proc. American Control Conf., Albuquerque, NM, June 1997, pp. 2647-2651. also J. Vibr. Contr., vol. 6, pp. 61-83 
[11] S.P. Bhat and D.S. Bernstein, "Finite-time stability of homogeneous systems," in Proc. Amer. Contr. Conf., Albuquerque, NM, 1997, pp. 2513-2514.

[12] J. Hong and D.S. Bernstein, "Experimental application of direct adaptive control laws for adaptive stabilization and command following," in Proc. Conf. Dec. Contr., Phoenix, AZ, 1999, pp. 779-783.

[13] M.M. Gupta and N.K. Sinha, "Intelligent Control Systems Theory and Applications”, IEEE Press, New York 1996.

[14] J.M. Mendel, "Fuzzy Logic Systems for Engineering: A Tutorial", Proceedings of the IEEE, VOL. 83, No. 3, pp. 345-377, March 1995.

[15] Woo, Z.; Chung, H.; Lin, J :" A PID type Fuzzy Controller with Self-Tuning scaling factors." In: Fuzzy Sets and Systems 115 (2000), pp. 321 - 326.

[16] Mudi, R. K.; Pal, N. R.: "A Self-Tuning Fuzzy PI Controller." In: Fuzzy Sets and Systems 115 (2000), pp. 327 - 338.

[17] Palm, R.: Scaling of Fuzzy Controller Using the Cross-Correlation. In: IEEE Trans. Fuzzy System. Vol. 3, 1995, pp. $116-123$.

[18] O' Mahony, T., Downing,C.J. and Klaudiuz, F., "Genetic Algorithms for PID Parameter Optimisation: Minimising Error Criteria", [online], URL: http://www.pwr.wroc.pl/ i-8zas/kf_glas00.pdf

[19] Linkens, D.A., \& H.O. Nyongesa, "Genetic algorithms for fuzzy control", IEE Proc. Control Theory Appl., Vol. 142, No. 3, pp.161-185

[20] Whitley, "A Genetic Algorithm Tutorial," Technical Report CS-93-103, Dept. Of Computer Science, Colorado State University, 1993

[21] DC. R. Houck, J. Joines. and M.Kay. A genetic algotithm for function optimisation: A Matlab implementation. ACM Transactions on Mathematical Software, 1996, [Online], URL:

http://www.eos.ncsu.edu/eos/service/ie/research/kay_res/GAToolBox/gaot

[22] Ogata k. "Modern Control Engineering", $2^{\text {nd }}$ Ed ,prentice-hall 1991.

\section{تصميم المعوضات المختلفة لنظم المتكاملات المزدوجة}

يتناول هذا البحث تحليلاً لتصميم وبناء العديد من الحاكمات أو المعوضات المختلفة

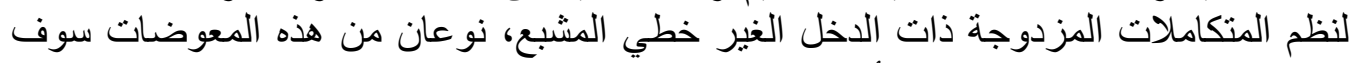

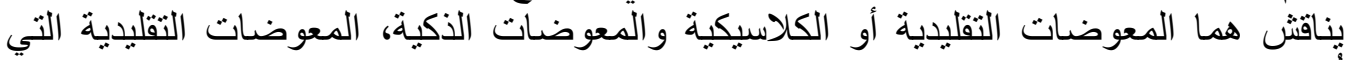
أستخدمت هي حاكم التناسبية التفاضلية، ،حاكم الباب الخلفي والحاكم الجاوسي التربيعي كمثال للحاكمات الخطية، وحاكم ادني وقت، حاكم الطاقة الدنيا، حاكم منزلق متقطع، حاكم الإشباع،

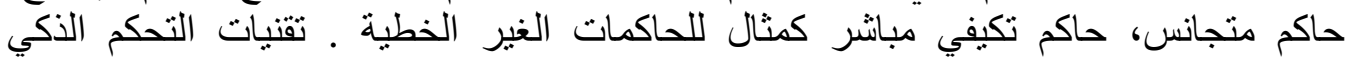
المستخدمة هي المنطق الغيمى، وحاكم تناسبي تفاضلي تكاملي مستخدم للتقنية منغم الخوارزميات الَّراثية، و البحث يقدم در اسة نظرية للمقارنة بين طرق مختلفة للتحكم في سر عة فئ وزاوية جسم حر الحركة أو ثنائي التكامل.

وتم إثبات أن النظام دائم الإتزان لأي تغير في القيم البدائية للسر عة والزاوية عن طريق رسم

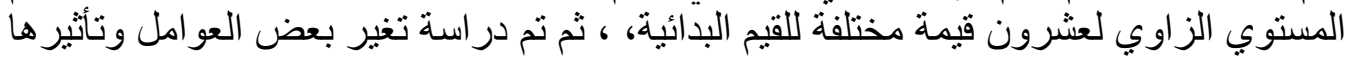

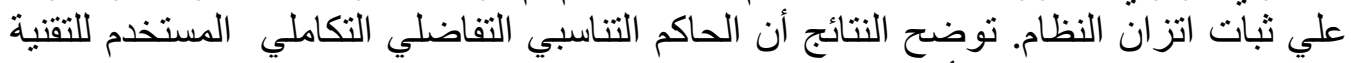
منغم الخوارزميات الور اثية أفضل بالمقارنة مع باقي الحاكمات المستخدمة. 